\title{
Evaluation of damage mechanics of industrial wind turbine gearboxes
}

\author{
V Jantara Junior, J Zhou, S Roshanmanesh, F Hayati, S Hajiabady, XY Li, H Dong and M Papaelias \\ In recent years, global wind power capacity has grown steadily at an annual rate of around $20 \%$. This has led to wind \\ energy becoming the most important renewable energy source on a global scale, with the total installed capacity \\ reaching $430 \mathrm{GW}$. However, the strong growth of offshore wind power has been somewhat inhibited due to a number \\ of operational challenges that are yet to be addressed in full. The most important of these challenges appears to be \\ the reliability of the wind turbine gearbox (WTG). WTGs are currently unable to survive their anticipated design lifetime \\ of 20-25 years. Most of them hardly reach a useful operational lifetime of more than seven years without serious \\ refurbishment or replacement and, for offshore wind turbines, failures have been reported as early as within one to \\ two years. In this paper, the damage mechanisms influencing WTGs supported by finite element analysis have been \\ considered and presented in the context of condition monitoring diagnosis and prognosis.
}

Keywords: wind turbines, gearbox, FEA, condition monitoring, acoustic emission.

\section{Introduction}

In order to be cost effective, a wind turbine must achieve its intended design lifetime. Although wind turbines are designed to last at least 20 years, the wind energy industry has suffered from premature gearbox failures from its inception. Given that gearboxes are amongst the most expensive sub-systems of utility-scale wind turbines, their premature failure increases the cost of wind energy production considerably ${ }^{[1-8]}$. Direct-driven design configurations also exist and have been developed to remove the need for a gearbox. However, direct-drive designs are heavier and more expensive when compared to geared wind turbine models $s^{[9]}$. Tavner et al discuss $\mathrm{in}^{[10]}$ that the failure rate of the power electronics in direct-drive wind turbines is very significant and when the inverter is considered together with the electronics, the failure rate greatly exceeds that of the gearbox.

Approximately $75 \%$ of all commercial wind turbines employ three-stage gearboxes, combining parallel, helical or spur gears together with planetary gears. Hybrid designs based on mediumspeed drivetrains have been in use in larger wind turbines with power ratings above $5 \mathrm{MW}^{[11,12]}$. Wind turbines convert rotor torque to electrical power by employing a speed multiplier gearbox and an induction generator. The gearbox increases the turbine shaft rotational speed $(8-25 \mathrm{r} / \mathrm{min})$ to the speed required for the generator to produce power (1100-1800 $\mathrm{r} / \mathrm{min}$ ), while reducing torque by the same ratio. The great benefit of geared wind turbines is that the high speed produced by the generator allows the use of a smaller generator in comparison with direct-driven wind turbines, thus saving in the total weight of the nacelle and the cost of wind turbine.

The conditions under which wind turbine gearboxes operate are different to those of other gearboxes used in conventional steadystate applications. The loads to which they are subjected vary with the aerodynamic torque applied on the blades. There are also other external electomechanical failures that can generate shock loads, as well as lateral loads that can be transferred to the gearbox. The lack of satisfactory understanding of the stochastic and cyclic loads, as well as misalignment of the high-speed shafts and lack of proper lubrication, are some of the causes of the premature failure of gearboxes ${ }^{[13]}$. Moreover, the failure mechanics are not yet fully understood ${ }^{[2,14]}$.
The replacement of a gearbox involves significant downtime and cost, including the costs of hiring the crew and equipment required for the replacement. Surface-treated Cr-based ferrous alloys are normally used in the manufacture of gearbox rolling elements. According to the wind turbine gearbox design recommended by the American Gear Manufacturers Association (AGMA) ${ }^{[15]}$, the core hardness of external gears must be in the range of 290-450 HV. In order to improve their durability, gear components are also surface hardened ${ }^{[16]}$. All processing and gear materials need to meet the requirements of ISO 6336-5 $5^{[17]}$. Wind turbine gears are often manufactured from low-carbon, high-chromium and molybdenum steels such as 4320, 4820, 9310 and 18CrNiMo7$6^{[18]}$. For carburised gears, nickel and molybdenum in the right combination provide maximum toughness. They also resist grain coarsening during austenitising ${ }^{[19]}$.

\section{Gearbox failure mechanisms}

The most common structural faults experienced by wind turbine gearboxes are gear tooth and bearing damage, followed by broken shafts. Bearing failures tend to be the root cause of the majority of wind turbine gearbox failures. These occur mostly due to micropitting, scuffing, false brinelling and fretting corrosion ${ }^{[20,21]}$. A brief explanation for some of these failure modes is provided.

Micropitting is normally a precursor of surface damage and both

- Based on a paper presented at WCCM 2017, the First World Congress on Condition Monitoring, 13-16 June 2017, London, UK. This paper was a winner of the Len Gelman Award for the best paper in the proceedings by a person in the early stages of their career.

Valter Jantara Junior, Jun Zhou, Sanaz Roshanmanesh, Siavash Hajiabady, Xiao Ying Li, Hanshan Dong and Mayorkinos Papaelias* are with the School of Metallurgy and Materials, University of Birmingham, UK.

Farzad Hayati is with the School of Engineering, University of Birmingham, UK.

*Corresponding author. Email:m.papaelias@bham.ac.uk 
gears and bearings are affected by this mechanism. Micropitting arises from tangential shear stress caused by rolling and sliding contact. It occurs when the oil layer does not have enough thickness in order to detach the contact surfaces and when they are sliding against one another ${ }^{[16,20]}$. Micropitting changes the geometry of the raceways and rollers, subsequently causing rapid degradation. The geometrical changes give rise to an increase of the internal clearance, causing high edge stresses that eventually lead to macropitting and final bearing failure ${ }^{[22]}$. Scuffing is a surface damage mode often characterised by a high level of plastic deformation. When the thickness of the lubrication film is inadequate (generally due to high loads or increased speed), it causes local frictional heating at the surface, which is the main cause for scuffing. Even though mitigation methods are fairly well established for this type of failure, a better understanding is needed, since scuffing field failures are frequent ${ }^{[16,20]}$.

Contamination of the gearbox oil poses a serious problem. Particle contamination can cause abrasive wear and initiate surface fatigue spalling, resulting in a significant reduction in the service lifetime of gear lubricants ${ }^{[20-23]}$. Impurities are capable of entering the gearbox during manufacture, assembly or maintenance, produced by wear or admitted by breathers and seals. The use of smooth surfaces, surface-hardened gears and high-viscosity lubricants can minimise the internal generation of wear debris ${ }^{[24]}$. Moisture ingression can be a catalyst of micropitting ${ }^{[25]}$, causing the effective viscosity of the lubricant to be altered. Changes in oil viscocity will consequently alter the oil film between the contact surfaces ${ }^{[20,26]}$.

The harsh operational environment under which wind turbine gearboxes operate result in a lack of adequate understanding of the effect of dynamic stochastic loads in accurately determining the fatigue lifetime of rolling components. Drivetrain components experience instant and long-term misalignments of the gear mesh, as well as bending of the gearbox shafts due to the strong dynamic loading variability effect ${ }^{[20]}$

\section{Wind turbine condition monitoring}

Condition monitoring systems are extensively used to evaluate the condition and quantify the reliability of in-service industrial machinery, including wind turbine gearboxes. The main concept behind condition monitoring is to choose a quantifiable machinery parameter that changes as the condition of the machinery or its subcomponents deteriorates. By monitoring certain pre-chosen parameters, it is possible to detect and quantify changes that can then be linked to the actual condition of the machinery being monitored, enabling diagnosis of a fault ${ }^{[27]}$.

The application of remote condition monitoring systems aims to identify faults as early as possible, preventing the likelihood of catastrophic failure and unnecessary loss of production and consequently allowing repairs to be carried out in time $e^{[1,3]}$. As wind turbines become larger and more expensive, the need to monitor their performance and foresee damage initiation and the rate of propagation has increased. Remote condition monitoring systems have become standard as a means of improving the reliable operation of wind turbines. In this way, the profitability of wind farms can be maximised through the reduction of downtime, allowing higher availability, and hence capacity, to be achieved.

Vibration analysis is the most popular technique for monitoring onshore and offshore wind turbines ${ }^{[1,3]}$. It is important to note that the capability of remote condition monitoring systems relies on the number and types of sensor used, the location of installation, data acquisition and the processing methodology followed.

Modern wind farms incorporate supervisory control and data acquisition (SCADA) systems that are responsible for connecting the wind farm and meteorological stations at the wind farm site to the dispatch centre of the wind farm operator. These systems usually monitor variables such as temperature, lubricating oil health and vibration levels of the drivetrain. Degradation of, or damage to, the gearbox may be present in several forms, such as debris, vibration, additional heating or acoustic emission. Therefore, vibration analysis, oil debris analysis and acoustic emission monitoring can be used to effectively monitor the gearbox condition ${ }^{[1,3]}$. It is noteworthy to mention at this point that no single technique can detect all possible failure modes since each of them has its own strengths and limitations ${ }^{[1,3]}$.

\section{Surface engineering}

Gear failures caused by rolling contact fatigue mechanisms are common. In order to achieve a long lifetime, gears must have a tough core in order to withstand fatigue bending stresses and a hard surface to reduce the damage caused by rolling contact fatigue. To achieve such versatile mechanical properties, effective surface treatment processes, such as carburising and nitriding, need to be employed. Both surface treatment methods generate residual compressive stresses in the outer skin of the material, increasing its fatigue properties. Duplex surface engineering is an alternative way of achieving the required properties by combining two or more surface treatment processes.

Gears used in high-performance applications, such as wind turbines, need to work under high torque for power transmission, a situation that can hardly be reached solely by carburising or nitriding ${ }^{[28]}$. Several studies ${ }^{[28-30]}$ have concluded that duplex treatment can enhance the technical properties of components. Duplex surface engineering is based on the consecutive application of two or more surface treatments, in order to generate a composite surface with synergetically-combined properties ${ }^{[28]}$.

Diamond-like carbon (DLC) coatings, also known as diamondlike coatings or amorphous hydrocarbon coatings (a-C:H), are very efficient since they exhibit very low friction against most types of contact surface ${ }^{[28]}$. However, they also tend to be brittle and are not suitable for high-load applications ${ }^{[31-32]}$. DLC coatings are generally distinguished by high residual stress levels, as well as low adhesion when applied right onto the greater part of engineering materials. Dong and Bell ${ }^{[30]}$ overcame this obstacle by applying a gradient layer between the DLC and the substrate.

\section{Effect of variables on contact stress}

The level of contact stress in relation to the increasing coefficient of friction was modelled for the surfaces of two gear teeth in contact using Abaqus ${ }^{\oplus}$. The plot in Figure 1 shows the results obtained. It can be clearly seen that as the coefficient of friction increases, contact stress also increases due to an increase in the friction force generated at the contact surfaces.

Similarly, in order to test the effect of angular misalignment, one of the gears was rotated along its $y$-axis, between $0^{\circ}$ and $1^{\circ}$. The results can be seen in Figure 2. It can be noticed that the angular misalignment has a great effect on the contact stress. Even a small misalignment, such as $0.2^{\circ}$, can produce contact stresses as high as 692.7 $\mathrm{MPa}$, which is almost 3.3 times the contact stress obtained from two gears meshing in perfect alignment.

At $1^{\circ}$ of angular misalignment, the contact stress can be almost 18 times higher than the initial contact stress. Such high contact stresses could lead to plastic deformation, eventually causing catastrophic failure of the gear teeth. 


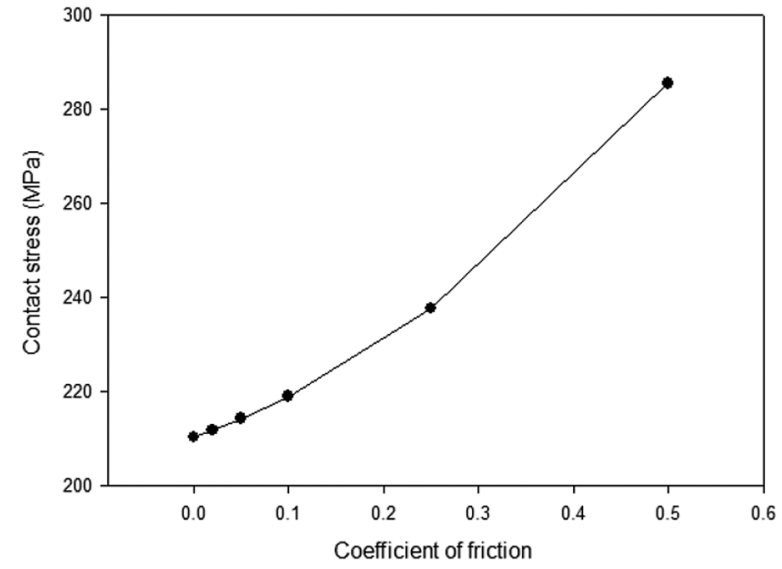

Figure 1. Effect of the coefficient of friction on contact stress

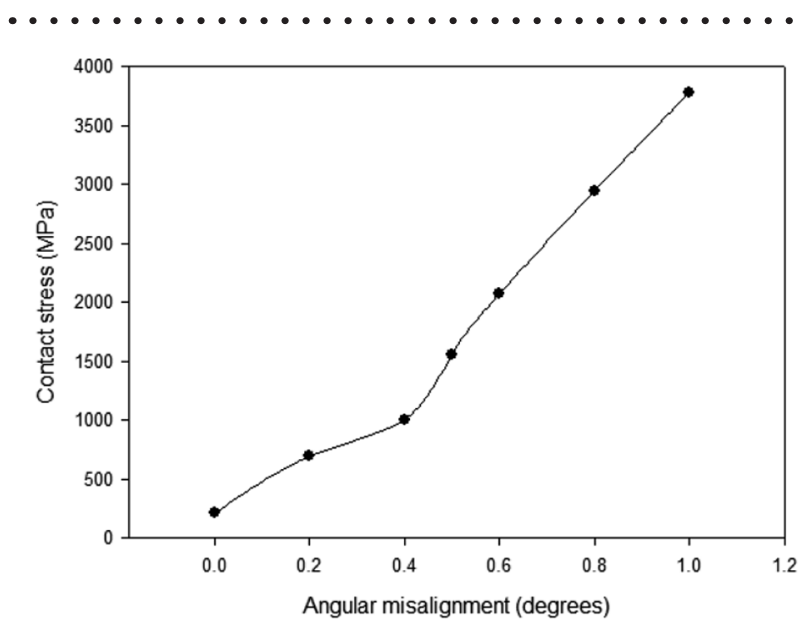

Figure 2. Effect of angular misalignment on contact stress

In order to evaluate the effect of radial misalignment, one of the gears was translated along the $x$-axis, from $0 \mathrm{~mm}$ (Figure 3(a)) to $1.5 \mathrm{~mm}$ (Figure 3(b)). The results can be seen in Figure 4.

The radial misalignment also increases the contact stress, but not as much as the angular misalignment. As it can be seen, the values obtained for contact stress due to radial misalignment are not linear. However, it is important to notice that any radial misalignment produces a contact stress higher than the contact stress at perfect alignment. The highest stress was observed at a misalignment of $1.25 \mathrm{~mm}$. This is more than double the contact stress during perfect alignment.

\section{Failure analysis}

A broken gear tooth from the intermediate stage of a failed wind turbine gearbox was obtained for investigation. Figure 5 shows the flank of the tooth. It is possible to distinguish the occurrence of scuffing, flaking and plastic flow and discolouration.

The discoloured areas are due to overheating caused by lack of lubrication. Scuffing also occurs due to inadequate lubrication and causes local frictional heating at the surface. Flaking, in turn, occurs when cracks in the subsurface of the material propagate to the surface, causing the material to be removed or delaminated.

The root of the tooth is shown in Figure 6, where it is possible to see the fractured surface that exhibits typical characteristics of combined fatigue and ductile fracture mechanics. This is confirmed in Figure 7, where a dimpled surface in the fractured area associated with ductile failure due to large plastic deformation is observed. The

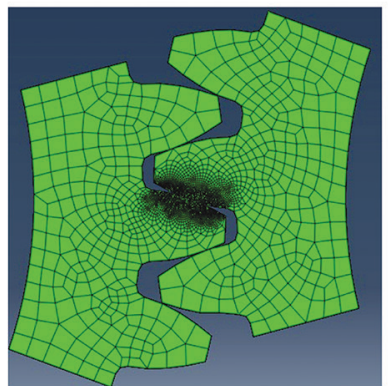

(a)

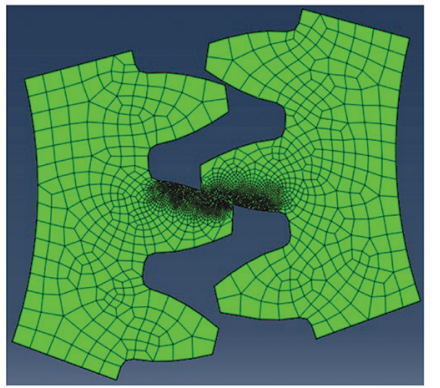

(b)
Figure 3. (a) Gear pair in perfect alignment; (b) gear pair in radial misalignment $(1.5 \mathrm{~mm})$

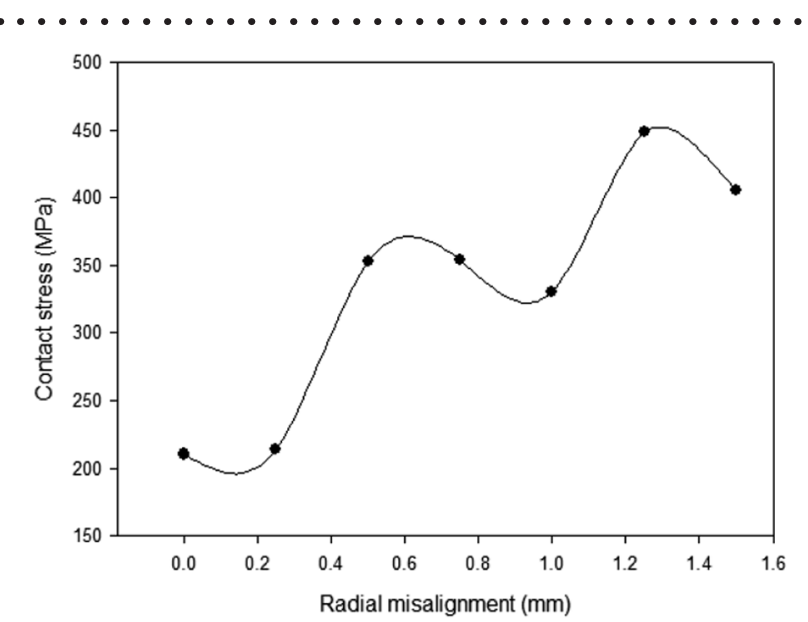

Figure 4. Effect of radial misalignment on contact stress

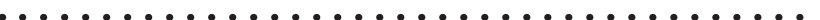

dimples are formed due to the coalescence of microvoids.

A cross-section of the broken tooth was then cut and prepared for metallographic analysis. Its microstructure predominantly comprises tempered martensite, as shown in Figure 8.

Some inclusions were also found. They were characterised via EDS and found to be MnS, as shown in Figure 9. The analysis revealed $\mathrm{Mn}, \mathrm{Si}, \mathrm{Cr}$ and $\mathrm{Ni}$ as alloying elements.

These inclusions found in the microstructure can act as crack initiation points under high contact stress conditions. Several examples of this behaviour were found near the failure area of the gear tooth. Two examples can be seen in Figure 10.

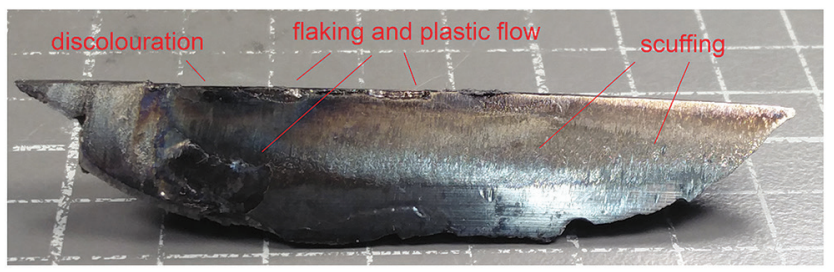

Figure 5. Side view of the broken tooth retrieved from the gearbox of an industrial wind turbine. Each square measures $1 \times 1 \mathrm{~cm}$

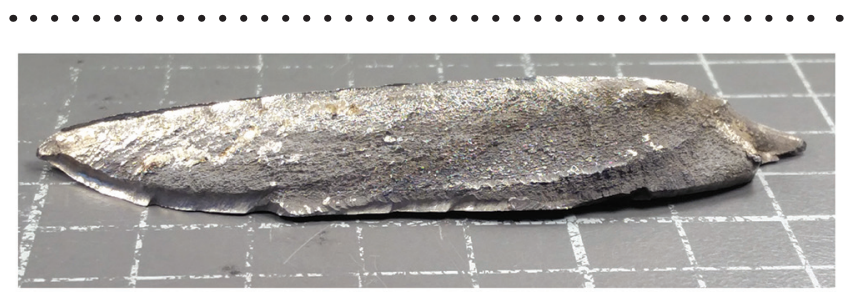

Figure 6. Root of broken tooth 


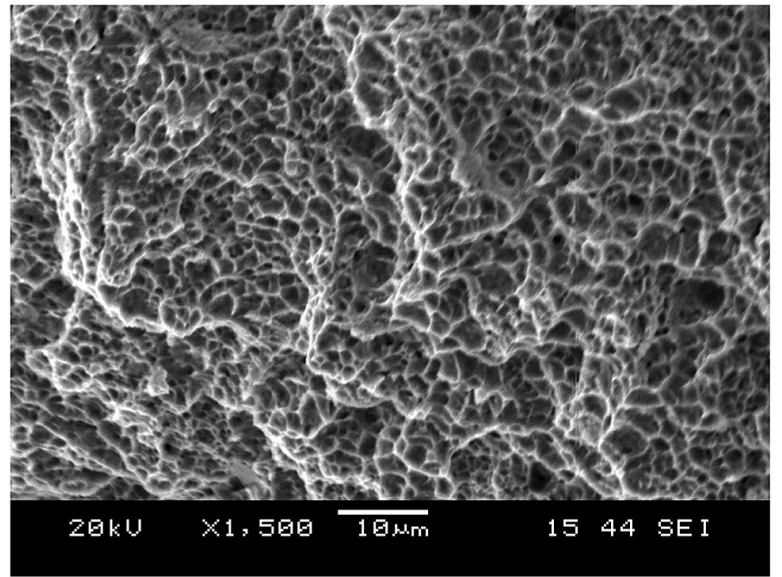

Figure 7. SEM image of the root of the broken tooth, showing a dimpled surface with $1500 \times$ magnification

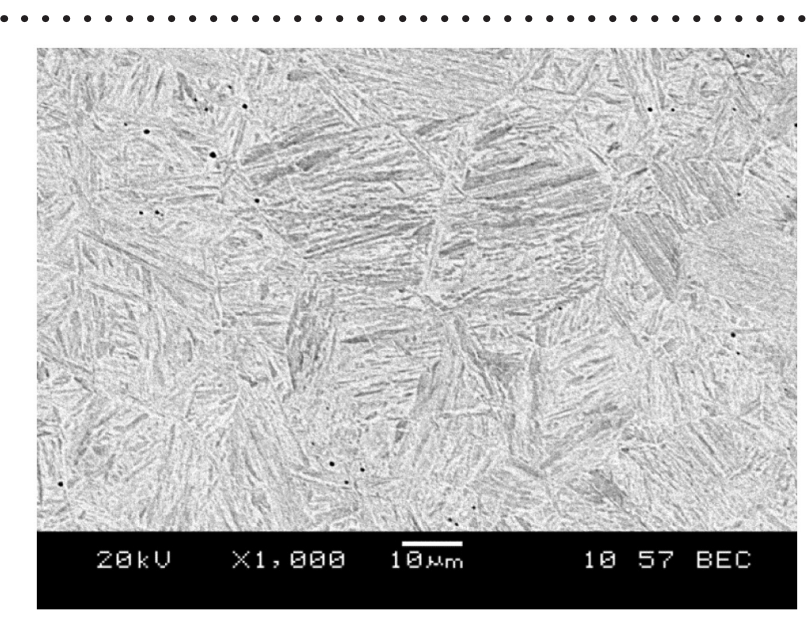

Figure 8. SEM micrograph of the gear tooth showing the tempered martensite microstructure at $1000 \times$ magnification

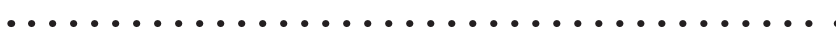

The hardness profile of the gear tooth is shown in Figure 11. The gear is much harder at the case than at the core due to carburisation. The depth of the case is up to $1 \mathrm{~mm}$. The evidence suggests that the primary mode of failure of this gear was caused by lubrication starvation. The lack of lubricant generated scuffing and heating at the tooth surface, while also increasing the frictional forces.

This, in turn, increased the stresses at the gear surface, which accelerated the wear and scuffing, with cracks nucleating and propagating from and along $\mathrm{MnS}$ inclusions. The new damaged surface created a non-uniform loading distribution, which led to plastic flow and finally ductile failure, as shown earlier in Figure 6.

\section{Conclusions}

The failure mechanisms affecting gearbox components can be very complex in nature. Despite advances in condition monitoring technology, the adverse operational conditions of wind turbines make accurate evaluation very difficult. Although successful diagnosis is more likely, effective prognosis still remains elusive. Prognosis requires far more information to be available in terms of material properties as well as failure mechanisms.

\section{Acknowledgements}

The authors gratefully acknowledge the financial support of the European Commission through the OPTIMUS FP7 project. OPTIMUS (demonstration of methods and tools for optimisation

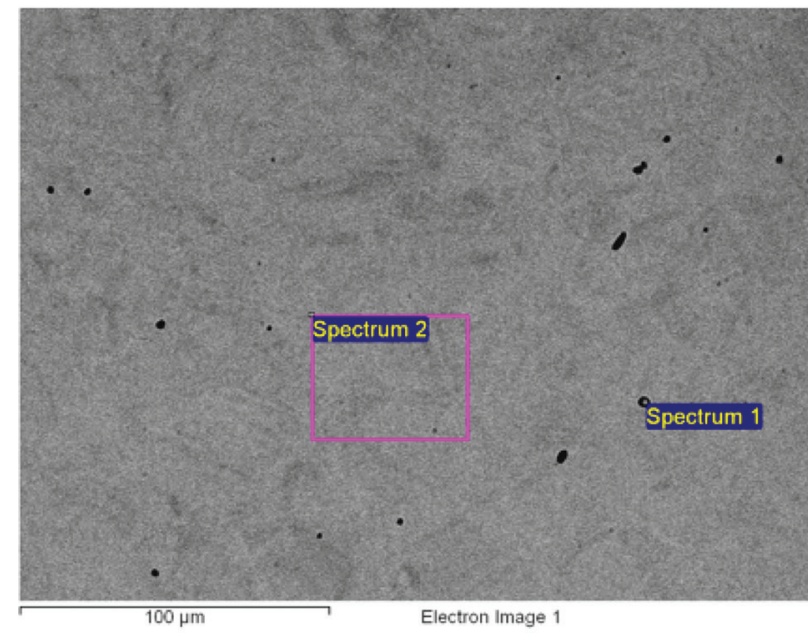

\begin{tabular}{|c|c|c|}
\hline Chemical element & Spectrum 1 (wt\%) & Spectrum 2 (wt\%) \\
\hline $\mathrm{C}$ & 3.76 & 1.46 \\
\hline $\mathrm{Si}$ & - & 0.21 \\
\hline $\mathrm{S}$ & 30.27 & - \\
$\mathrm{Cr}$ & 0.31 & 1.67 \\
$\mathrm{Mn}$ & 60.98 & 0.5 \\
\hline $\mathrm{Ni}$ & - & 1.39 \\
$\mathrm{Fe}$ & 4.68 & 94.79 \\
\hline
\end{tabular}

Figure 9. SEM micrograph of the gear tooth EDS results

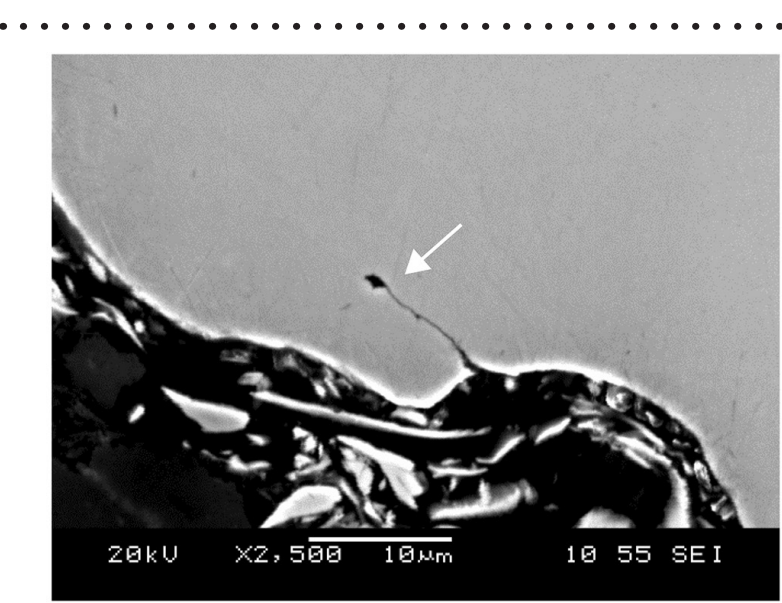

(a)

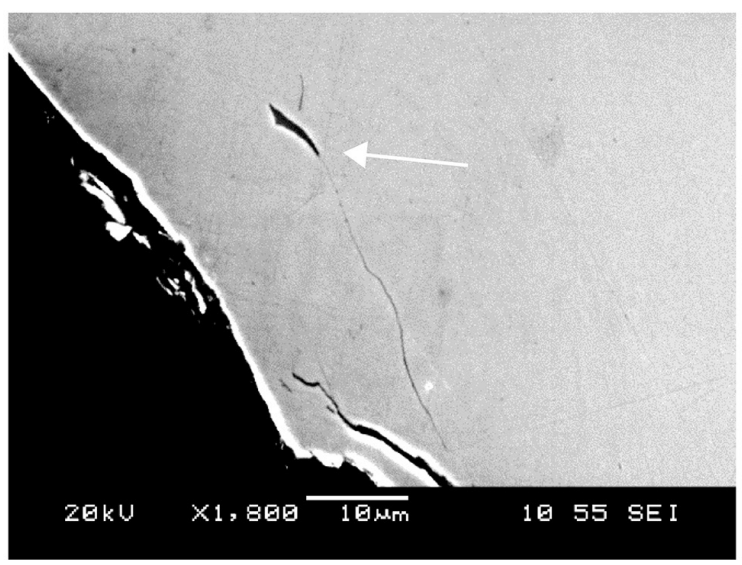

(b)

Figure 10. SEM micrographs of MnS inclusions nucleating cracks at (a) $2500 \times$ magnification and (b) $1800 \times$ magnification 


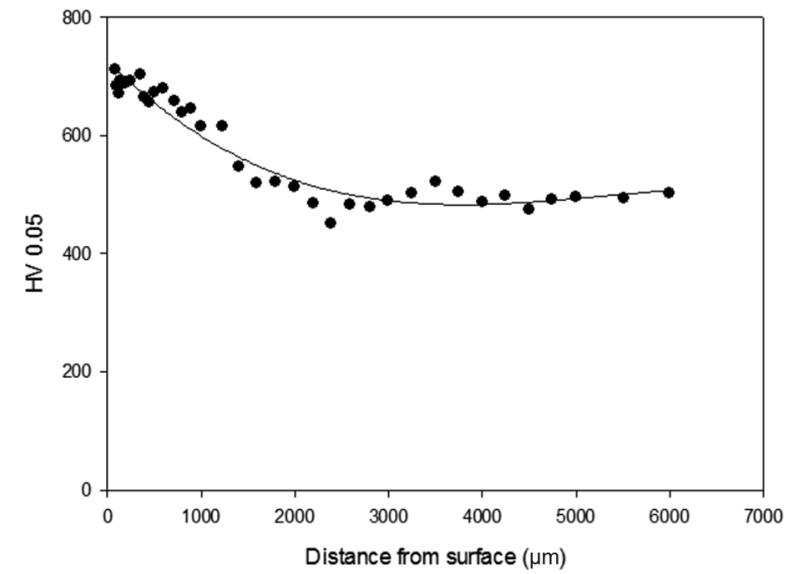

Figure 11. Microhardness profile for the gear tooth

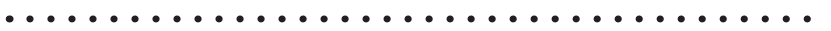

of operational reliability of large-scale industrial wind turbines) is a cooperation between the following organisations: The University of Birmingham, ENGITEC Limited, OREC, INGETEAM Service, ACCIONA ENERGIA, Instituto de Soldadura E Qualidade, INDRA Sistemas, Universidad de Castilla-La Mancha, Dynamics, Structures and Systems International, The University of Sheffield, Romax Technology and TERNA Energy. The project is managed by OREC and is a partly-funded project by the European Commission under the FP7 framework programme (Grant Agreement No: 322430). The authors also wish to express their appreciation to the National Council of Technological and Scientific Development of Brasil $(\mathrm{CNPq})$ for the financial support received through the Science without Borders Scheme.

\section{References}

1. J M P Pérez et al, 'Wind turbine reliability analysis', Renewable and Sustainable Energy Reviews, Vol 23, pp 463-472, 2013.

2. D A Spera, Wind Turbine Technology: Fundamental Concepts of Wind Turbine Engineering, 2nd edition, A Press, New York, 2009.

3. F P G Márquez et al, 'Condition monitoring of wind turbines: Techniques and methods', Renewable Energy, Vol 46, pp 169$178,2012$.

4. W Musial, S Butterfield and B McNiff, 'Improving wind turbine gearbox reliability', National Renewable Energy Laboratory, Milan, Italy, 2007

5. J Zhou et al, 'Improving the reliability of multi-MW wind turbines', Insight: Non-Destructive Testing and Condition Monitoring, Vol 59, No 4, April 2017.

6. J L F Chacon et al, 'An experimental study on the applicability of acoustic emission for wind turbine gearbox health diagnosis', Journal of Low Frequency Noise, Vibration and Active Control, Vol 35, No 1, pp 64-76, 2016.

7. J E Camacho Questa et al, 'Optimisation of operational reliability of large-scale industrial wind turbines', Renewable Energies Offshore - 1st International Conference on Energies Offshore, RENEW, Lisbon, Portugal, 2014.

8. S Hajiabady, S Kerkyras, S Hillmansen, $\mathrm{P}$ Tricoli and $\mathrm{M}$ Papaelias, 'Efficient condition monitoring for industrial wind turbines', 3rd Renewable Power Generation Conference (RPG 2014), Napoli, Italy, 24-25 September 2014

9. H Polinder et al, 'Comparison of direct-drive and geared generator concepts for wind turbines', IEEE Transactions on Energy Conversion, Vol 21, No 3, pp 725-733, 2006.

10. P J Tavner, G J W Van Bussel and F Spinato, 'Machine and converter reliabilities in wind turbines', IEEE 2nd International Conference on Power Electronics, Machine and Drives, Dublin, 2006.

11. S Schmidt and A Vath, 'Comparison of existing mediumspeed drivetrain concepts with a differential gearbox approach', European Wind Energy Association Annual Event, Copenhagen, Denmark, 2012.

12. J Helsen et al, 'Insights in wind turbine drivetrain dynamics gathered by validating advanced models on a newly developed 13.2 MW dynamically-controlled test-rig', Mechatronics, Vol 21, pp 737-752, 2011.

13. S Struggl, V Berbyuk and H Johansson, 'Review on wind turbines with focus on drivetrain system dynamics', Wind Energy, Vol 18, pp 567-590, 2015,

14. J Coultate et al, 'An investigation into the effect of lateral and axial aerodynamic loads on wind turbine gearbox reliability', European Wind Energy Conference and Exhibition, Marseille, France, 2009.

15. AGMA 6006-A03, Standard for Design and Specification of Gearboxes for Wind Turbines, 2004.

16. A Greco et al, "Friction and wear behaviour of boron-based surface treatment and nano-particle lubricant additives for wind turbine gearbox applications', Wear, Vol 271, No 9, pp 1754-1760, 2011.

17. ISO 6336-5, Calculation of load capacity of spur and helical gears, Part 5: Strength and quality of materials, 2003.

18. M LaPlante, 'Carburising wind turbine gears', Gear Solutions Magazine, Vol 5, pp 32-37, 2009.

19. R Errichelo, Application requirements for wind turbine gearboxes, NREL Report, 1994.

20. M N Kotzalas and G L Doll, 'Tribological advancements for reliable wind turbine performance', Philosophical Transactions of the Royal Society A - Mathematical Physical and Engineering Sciences, Vol 368, pp 4829-4850, 2010.

21. M Nie and L Wang, 'Review of condition monitoring and fault diagnosis technologies for wind turbine gearbox', Procedia CIRP, Vol 11, pp 287-290, 2013.

22. S Sheng, 'Wind turbine micropitting workshop: a recap', National Renewable Energy Laboratory, 2010.

23. W M Needelman, M A Barris and G L LaVallee, 'Contamination control for wind turbine gearboxes', Power Engineering, Vol 113, No 11, p 112, 2009.

24. R Errichello and J Muller, 'Oil cleanliness in wind turbine gearboxes', Machinery Lubrication, Vol 2, No 4, pp 34-40, 2002.

25. G L Livingstone, J Ameye and D Wooton, 'Optimising a wind turbine oil condition monitoring programme', Journal of ASTM International, Vol 8, No 10, pp 1-11, 2011.

26. T W Verbruggen, 'Wind turbine operation and maintenance based on condition monitoring', WT- $\Omega$, Final report, ECN-C03-047, 2003.

27. B K N Rao, Handbook of Condition Monitoring, Elsevier Science Ltd, 1996.

28. T Bell, H Dong and Y Sun, 'Realising the potential of duplex surface engineering', Tribology International, Vol 31, No 1, pp 127-137, 1998.

29. J C A Batista, C Godoy and A Matthews, 'Impact testing of duplex and non-duplex (Ti, Al) N and Cr-N PVD coatings', Surface and Coatings Technology, Vol 163, pp 353-361, 2003.

30. H Dong and T Bell, 'Designer surfaces for titanium components', Anti-Corrosion Methods and Materials, Vol 46, No 3, pp 181$188,1999$.

31. R Martins, R Amaro and J Seabra, 'Influence of low-friction coatings on the scuffing load capacity and efficiency of gears', Tribology International, Vol 41, No 4, pp 234-243, 2008.

32. D G Teer, 'New solid lubricant coatings', Wear, Vol 251, No 1, pp 1068-1074, 2001. 